\title{
The thermochemical non-equilibrium scale effects of the high enthalpy nozzle
}

\author{
Junmou Shen ${ }^{*}$ (D), Hongbo Lu, Ruiqu Li, Xing Chen and Handong Ma
}

\author{
* Correspondence: shenjunmou@ \\ 163.com \\ China Academy of Aerospace and \\ Aerodynamics, Beijing 100074 \\ China
}

\begin{abstract}
The high enthalpy nozzle converts the high enthalpy stagnation gas into the hypervelocity free flow. The flow region of the high enthalpy nozzle consists of three parts: an equilibrium region upstream of the throat, a non-equilibrium region near the throat, and a frozen region downstream of the throat. Here we propose to consider the thermochemical non-equilibrium scale effects in the high enthalpy nozzle. By numerically solving axisymmetric compressible Navier-Stokes equations coupling with Park's two-temperature model, the fully non-equilibrium solution is employed throughout the entire nozzle. Calculations are performed at different stagnation conditions with the different absolute scales and expansion ratio. The results of this study are twofold. Firstly, as the absolute scale and expansion ratio increase, the freezing position is delayed, and the flow approaches equilibrium. Secondly, the vibrational temperature and Mach number decrease with the increase in the nozzle scale and expansion ratio, while the speed of sound, static pressure, and translational temperature increase as the nozzle scale and expansion ratio increase,
\end{abstract}

Keywords: High enthalpy nozzle, Hypervelocity free flow, Thermochemical nonequilibrium flow, Scale effects

\section{Introduction}

An important characteristic of non-equilibrium is its scale effects [1]. A large deal of research focuses on the scale effects of the test model and the actual aircraft [1, 2], but little research has been published on the scale effects of the high enthalpy nozzle [3], especially the thermochemical non-equilibrium scale effects on the high enthalpy tunnel simulation ability. There are many high enthalpy tunnels in the world, such as TCM2 [4], HEG [5], T4 [6], T5 [6], HIEST [6], JF-10 [7], LENS I [8], and FD-21 [9]. Due to the complexity and difficulty of the hypervelocity simulation, a great number of national and international space and hypersonic flight projects have been carried out extensively, such as integrated scramjet configuration [10], complex hypersonic flight configuration [10], and hypersonic boundary layer transition [11]. The experimental data obtained from the same test model is different under the similar stagnation gas and boundary condition. Except for the factors of the flowfield quality of the high enthalpy tunnel, the diameters of the high enthalpy nozzles range from $0.4 \mathrm{~m}$ to $2.0 \mathrm{~m}$.

(c) The Author(s). 2020 Open Access This article is licensed under a Creative Commons Attribution 4.0 International License, which permits use, sharing, adaptation, distribution and reproduction in any medium or format, as long as you give appropriate credit to the original author(s) and the source, provide a link to the Creative Commons licence, and indicate if changes were made. The images or other third party material in this article are included in the article's Creative Commons licence, unless indicated otherwise in a credit line to the material. If material is not included in the article's Creative Commons licence and your intended use is not permitted by statutory regulation or exceeds the permitted use, you will need to obtain permission directly from the copyright holder. To view a copy of this licence, visit http://creativecommons.org/licenses/by/4.0/. 
The flow regimes in hypervelocity nozzle flow exhibit two types of scale effects $[1,12]$. One of these scale effects, caused by viscosity, is confined to the boundary layer near the nozzle wall and can be avoided when simulating on the ground. The other is the thermochemical non-equilibrium scale effects, which must be taken seriously as it affects the entire flow field including the core flow region; it is this scale effect that is the focus of this article. The high enthalpy convergent-divergent nozzle flow is a complex process, especially nozzle divergence, because of the large range of Reynolds number scale and the high-temperature effects [13]. As evidenced in previous studies, there are three distinct flow regions: an upstream near the equilibrium region, a non-equilibrium region near the throat, and frozen flow not far downstream of the throat [12]. When the flow is nearly frozen, there are no longer the non-equilibrium scale effects in the expansion zone. The flow parameters and chemical species depend on the dissociation of non-equilibrium before the freezing point.

This paper investigates the thermochemical non-equilibrium scale effects of the high enthalpy nozzle by the numerical method. To verify the reliability of the numerical method, the HEG and TCM2 nozzles are used to calibrate. Because they have undergone many tests and numerical validation. Based on the HEG nozzle, the flow field of the halved normal scale, normal scale, doubled normal scale and quintupled normal scale is numerically calculated. This paper also calculates the halved normal scale and normal scale of the FD-21 nozzle and the different expansion ratio based on the FD-21 nozzle. FD-21 was built in China Academy of Aerospace Aerodynamics in 2016 and is the largest-scale free-piston shock tunnel in the world $[14,15]$.

At present, the three models of 5-species $\left(\mathrm{O}_{2}, \mathrm{~N}_{2}, \mathrm{NO}, \mathrm{O}, \mathrm{N}\right)$, 7-species $\left(\mathrm{O}_{2}, \mathrm{~N}_{2}, \mathrm{NO}\right.$, $\left.\mathrm{O}, \mathrm{N}, \mathrm{NO}^{+}, \mathrm{e}^{-}\right)$, and 11-species $\left(\mathrm{O}_{2}, \mathrm{~N}_{2}, \mathrm{NO}, \mathrm{O}, \mathrm{N}, \mathrm{NO}^{+}, \mathrm{O}^{+}, \mathrm{N}^{+}, \mathrm{O}_{2}{ }^{+}, \mathrm{N}_{2}{ }^{+}, \mathrm{e}^{-}\right)$are used to calculate the high enthalpy flow field $[1,6,8,11]$. The calculation results show that the flow field pressure, temperature, velocity and distribution of major chemical species are broadly coincident $[4,5,11]$. The ions of 7-species and 11-species, more than 5species belong to the microspecies, and the chemical energy contained in them is negligible relative to the total gas flow, so they do not affect the main flow and the thermochemical parameters [12]. When it comes to questions such as flow field ionization and radiation characteristics, it is necessary to use the 7-species or 11-species models.

The 5-species and 7-species are used to calculate the high enthalpy flowfield in this paper. The axisymmetric compressible Navier-Stokes equations with Park's twotemperature model [16] are solved with a multi-block finite volume method. The results show that the freezing point moves downstream as the nozzle scale and expansion ratio increase. The flowfield characteristics, such as static temperature, Mach number, and species mass concentration distribution, are related to its absolute position, namely the nozzle scale. The larger nozzle scale and expansion ration can effectively suppress thermochemical non-equilibrium flow, which are more suitable for simulating the flight environment. 


\section{Numerical methods}

\subsection{Governing equations and numerical method}

The unsteady dimensionless axisymmetric form of the Navier-Stokes equation for the 5 -species and 7-species air in the thermochemical non-equilibrium state can be expressed in the vector equation [17] as:

$$
\frac{\partial U}{\partial t}+\frac{\partial F}{\partial x}+\frac{\partial G}{\partial r}+M=\frac{1}{R e}\left(\frac{\partial F_{v}}{\partial x}+\frac{\partial G_{v}}{\partial r}+M_{v}\right)+W
$$

where the vector $U$ is the vector of conservative quantities. The vectors $F$ and $G$ represent the convective fluxes. The viscous terms $F_{v}$ and $G_{v}$ contain the transport term. The vectors $M$ and $M_{v}$ are the inviscid and viscous source terms. The vector $W$ represents chemical and vibrational terms. The term $R e$ is the Reynolds number. These quantities are given by the following expression:

$$
\begin{aligned}
U & =\left[\rho C_{i}(i=1, \ldots, n s), \rho u, \rho v, \rho E, \rho e_{V}\right]^{T} \\
F & =\left[\rho u C_{i}(i=1, \ldots, n s), \rho u^{2}+p, \rho u v, \rho u H, \rho u e_{V}\right]^{T} \\
G & =\left[\rho v C_{i}(i=1, \ldots, n s), \rho u v, \rho v^{2}+p, \rho v H, \rho v e_{V}\right]^{T} \\
M & =\frac{1}{r}\left[\rho v C_{i}(i=1, \ldots, n s), \rho u v, \rho v^{2}, \rho v H, \rho v e_{V}\right]^{T} \\
F_{v}= & {\left[\frac{L e_{i} k}{\operatorname{Pr} C_{p}} \frac{\partial C_{i}}{\partial x}(i=1, \ldots, n s), \tau_{x x}, \tau_{x r}, u \tau_{x x}+v \tau_{x r}+q_{x}, q_{v x}\right]^{T} } \\
G_{v}= & {\left[\frac{L e_{i} k}{\operatorname{Pr} C_{p}} \frac{\partial C_{i}}{\partial r}(i=1, \ldots, n s), \tau_{x r}, \tau_{r r}, u \tau_{x r}+v \tau_{r r}+q_{r}, q_{v r}\right]^{T} } \\
M_{v}= & \frac{1}{r}\left[\frac{L e_{i} k}{\operatorname{Pr} C_{p}} \frac{\partial C_{i}}{\partial r}(i=1, \ldots, n s), \tau_{x r}, \tau_{r r}-\tau_{\theta \theta}, u \tau_{x r}+v \tau_{r r}+q_{r}, q_{v r}\right]^{T} \\
W & =\left[\dot{w}_{i}(i=1, \ldots, n s), 0,0,0, S_{v}\right]^{T}(9)
\end{aligned}
$$

where $n s$ is the number of species, which is equal to 5 or 7. $\rho$ is the density of the mixture. $C_{i}$ is species mass fraction. $u$ and $v$ are the components of the velocity $V . r$ is the coordinate in the radial direction. $L e_{i}$ is the Lewis number of the species. $\operatorname{Pr}$ is the Prandtl number of the mixture. $k$ is the Coefficient of heat conduction. $C_{p}$ is the specific heat. $\tau_{x x}, \tau_{r r}, \tau_{x r}$, and $\tau_{\theta \theta}$ are the components of the viscous stress tensor. $w_{i}$ is the chemical source terms. $H$ is the total enthalpy. $\rho E$ is the total energy per unit volume, containing translational energy $\rho e_{\mathrm{t}}$, rotational energy $\rho e_{\mathrm{r}}$, vibrational energy $\rho e_{\mathrm{v}}$, electronic energy $\rho e_{\mathrm{e}}$, free energy $\rho e_{0}$, and the kinetic energy of the gas $\rho V^{2} / 2 . \rho E$ is expressed as:

$$
\begin{aligned}
& \rho E=\sum_{i=1}^{n s} \rho C_{i}\left(e_{t i}+e_{r i}+e_{e i}+e_{0 i}\right)+ \\
& \sum_{i=1}^{n t} C_{i} e_{v i}\left(T_{v}\right)+\frac{1}{2} \rho V^{2}
\end{aligned}
$$


where $n t$ is the number of species that remove electrons from $n s . q_{\mathrm{x}}, q_{\mathrm{r}}$ and $q_{\mathrm{vx}}, q_{\mathrm{vr}}$ are the components of the total heat flow and the vibrational heat flow in the $x$ and $r$ coordinates, respectively. They are expressed as:

$$
\begin{aligned}
& q_{n}=\frac{1}{\operatorname{Pr}}\left(k_{t} \frac{\partial T}{\partial n}+k_{v} \frac{\partial T_{v}}{\partial n}+\sum_{i=1}^{n s} h_{i} \frac{L e_{i} k}{C_{p}} \frac{\partial C_{i}}{\partial n}\right) \quad(n=x, r) \\
& q_{v n}=\frac{1}{\operatorname{Pr}}\left(k_{v} \frac{\partial T_{v}}{\partial n}+\sum_{i=1}^{n s} e_{v i} \frac{L e_{i} k}{C_{p}} \frac{\partial C_{i}}{\partial n}\right) \quad(n=x, r)
\end{aligned}
$$

$S_{\mathrm{v}}$ is the vibrational source terms of the species. It is expressed as:

$$
S_{v}=\rho \frac{e_{\nu}(T)-e_{\nu}\left(T_{v}\right)}{\tau_{v}}+\sum_{i=1}^{n s} \dot{w} e_{v i}
$$

\subsection{Non-equilibrium model}

For mixed gas, each species is considered as a perfect gas. The chemical source terms are derived from several reactions. The following equations are the 5-species air with 17-reaction scheme and 7-species air with 21-reaction scheme [18].

$$
\begin{aligned}
& \mathrm{O}_{2}+M_{1} \rightleftharpoons 2 \mathrm{O}+M_{1} \\
& \mathrm{~N}_{2}+M_{2} \rightleftharpoons 2 \mathrm{~N}+M_{2} \\
& \mathrm{NO}+M_{3} \rightleftharpoons \mathrm{N}+\mathrm{O}+M_{3} \\
& \mathrm{NO}+\mathrm{O} \rightleftharpoons \mathrm{N}+\mathrm{O}_{2} \\
& \mathrm{~N}_{2}+\mathrm{O} \rightleftharpoons \mathrm{NO}+\mathrm{O} \\
& \mathrm{NO}+M_{4} \rightleftharpoons \mathrm{NO}^{+}+e^{-}+M_{4} \\
& \mathrm{~N}+\mathrm{O} \rightleftharpoons \mathrm{NO}^{+}+e^{-} \\
& \mathrm{N}_{2}+\mathrm{O}_{2} \rightleftharpoons \mathrm{NO}+\mathrm{NO}^{+}+e^{-}
\end{aligned}
$$

where $M_{1}=\mathrm{N}, \mathrm{O}, \mathrm{NO}, \mathrm{N}_{2}$ and $\mathrm{O}_{2} ; M_{2}=\mathrm{N}, \mathrm{O}, \mathrm{NO}, \mathrm{N}_{2}$ and $\mathrm{O}_{2} ; M_{3}=\mathrm{N}, \mathrm{O}, \mathrm{NO}, \mathrm{N}_{2}$ and $\mathrm{O}_{2} ; M_{4}=\mathrm{N}_{2}$ and $\mathrm{O}_{2}$.

The coupling between chemical and vibrational processes is taken into account. The forward reaction rate $k_{f, r}$, and backward reaction rate $k_{b, r}$ of the dissociation equations are expressed in the modified Arrhenius form [17] as

$$
\begin{gathered}
k_{f, r}=A_{f, r} T_{a v}^{B_{f, r}} \exp \left(-T_{D_{f, r}} / T_{a v}\right) \\
k_{b, r}=A_{b, r} T_{t r}^{B_{b, r}} \exp \left(-T_{D_{b, r}} / T\right)
\end{gathered}
$$

where $A_{f, r}$ and $A_{b, f}$ are the forward and backward reaction rate constant. $T_{D f, r}$ and $T_{D b, r}$ are the characteristic reaction temperatures for the forward and backward reactions, respectively. Values for the reaction rates $k_{f, r}$ and $k_{b, r}$ are taken from reference [17] for the 5-species and 7-species air model. $T_{a v}$ is the geometric average temperature [16]:

$$
T_{a v}=\sqrt{T T_{\mathrm{v}}}
$$

where $T$ is the translational temperature, and $T_{\mathrm{V}}$ is vibrational temperature. The translational temperature $T$ is equal to the static temperature $T$. 
The mixture viscosity and thermal conductivity of the mixture are computed by applying Gupta-Yos viscosity fits [17] for each species.

$$
\begin{aligned}
& \mu_{s}=\exp \left(C_{\mu, s}\right) T^{\left(A_{\mu, s} \ln T+B_{\mu, s}\right)} \\
& k_{s}=\exp \left(E_{k, s}\right) T^{\left(A_{k, s}(\ln T)^{3}+B_{k, s}(\ln T)^{2}+C_{k, s}(\ln T)+D_{k, s}\right)}
\end{aligned}
$$

where $A_{\mu, s}, B_{\mu, s}, C_{\mu, s}, A_{\mathrm{k}, \mathrm{s}}, B_{\mathrm{k}, \mathrm{s}}, C_{\mathrm{k}, \mathrm{s}}, D_{\mathrm{k}, \mathrm{s}}$ and $E_{\mathrm{k}, \mathrm{s}}$ are constants. Wilke's Law [19] is then used to compute the bulk quantities.

For temperatures between $300 \mathrm{~K}$ and $8000 \mathrm{~K}$, the vibrational relaxation time $\tau_{i}$ is given by the following equation [20].

$$
\tau_{i}=\tau_{i, M W}+\tau_{i, P}
$$

where $\tau_{i, \mathrm{P}}$ is translational-vibrational energy relaxation time (TVERT) for the species $s$ from the report by Park [20]. $\tau_{i, \mathrm{MW}}$ is TVERT for the molecular species $s$ from the correction by Millikan and White [20].

$$
P \tau_{i, M W}=\frac{\sum_{i=1}^{n s} N_{i} \exp \left\lfloor A_{s}\left(T^{-1 / 3}-0.015 M_{s i}^{0.25}\right)-18.42\right\rfloor}{\sum_{i=1}^{n s} N_{i}}
$$

Where $P$ is pressure. $N_{i}$ is number density. $M_{s i}$ is reduced molecular weight of species. $A_{\mathrm{s}}$ is constant.

For a perfect gas, the speed of sound is given by $a^{2}=(\partial p / \partial \rho)_{s}$. For the nonequilibrium sound speed [1] $a_{\mathrm{n}}$, the corresponding expression can be written as

$$
a_{n}^{2}=-\left[\left(\frac{\rho h_{p}-1}{\rho h_{p}}\right)+\frac{1}{\rho u h_{\rho}\left(\frac{\partial p}{\partial r}\right)} \sum_{i}^{n s} h_{C_{i}} w_{i}\right]^{-1}
$$

where subscripts denote partial derivatives of specific enthalpy $h=h\left(p, \rho, C_{i}\right)$ for the variable: the pressure, density and specific mass fraction.

For the frozen sound speed $a_{\mathrm{f}}$, the gas assumes no reactions. $a_{\mathrm{f}}$ is the frozen sound speed defined by

$$
a_{f}^{2}=-\left[\left(\frac{\rho h_{p}-1}{\rho h_{p}}\right)\right]^{-1}
$$

The unsteady flow equations are integrated in time, which are solved for the convergent-divergent axisymmetric high enthalpy nozzle with given stagnation conditions and wall conditions. Jameson [21] fourth-order Runge-kutta method [21] is employed for time integration. The inviscid numerical fluxes are computed using a low-dissipation AUSM scheme [22], with a MUSCL scheme for a third-order spatial accuracy. For the physics of the strongly favorable pressure gradient around the nozzle throat, the Spalart-Allmaras one-equation turbulence model [23] with the CatrisAupiox compressibility correction is evaluated for the task. The chain rule is used to calculate the viscosity flux [24]. The exit boundary is dominated by hypersonic flow by diverging free stream conditions generated by the nozzle. All conservative variables are 
extrapolated. No-slip conditions for the solid walls. The wall conditions are given for a fully catalytic wall and an isothermal wall where $T_{\mathrm{w}}=600 \mathrm{~K}$.

\subsection{Physical model and grid generation}

As mentioned above, the TCM2 conical nozzle [4], the HEG conical nozzle [5], and the FD-21 conical nozzle [9] are studied. The TCM2 nozzle and HEG nozzle are calculated to verify the accuracy of the program. The HEG nozzle is halved normal scale (0.5NS), normal scale (NS), doubled normal scale (2NS) and quintupled normal scale (5NS). For the conical nozzle, the main dimensions contain the half cone angle (HCA), throat diameter $\left(d_{\mathrm{t}}\right)$, exit diameter $\left(d_{\mathrm{e}}\right)$ and the expansion ratio (ER, defined as the ratio of exit area to throat area). The normal scale TCM2 and HEG nozzles are recorded in Table 1. Cases 1 and 2 in Table 2 is the NS and 0.5NS of FD-21 nozzle, and Cases 3 and 4 change ER by changing the nozzle throat diameter.

A structured grid is used for all the numerical simulations. The grid consists of two blocks: one of the blocks is the shock tube part, which is $200 \mathrm{~mm}$ from the end of the shock tube in the axial direction; the other is the nozzle part. The structured grid is shown in Fig. 1. The total grid number is 251,250 . The grid system of the shock tube is $51 \times 201$ and the grid system of the nozzle part contains $1200 \times 201$. The system is used with $\Delta x_{\min }=1 \times 10^{-4} \mathrm{~m}$ located at the throat section, and $\Delta y_{\min }=2 \times 10^{-8} \mathrm{~m}$ at the wall. Exponential compression is used in the radial direction. A grid convergence study is conducted with three different grid resolutions (125,100; 150,120 and 251,250), and a small change in pressure, species, velocity, and Mach number distribution is registered. For each grid system, the $y^{+}$value is less than one.

\subsection{Conditions of numerical simulation}

The initial conditions are chosen from the data obtained by the TCM2 nozzle [4] and the HEG nozzle [5], which correspond to Case 1 and Case 2 in Table 3, respectively. The pressure, temperature and the species mass concentrations in stagnation conditions are obtained by equilibrium assumption and are reported in Table 3. The initial condition of FD-21 is also obtained from Case 2 in Table 3.

\section{Verification of calculation procedure}

\subsection{Precision estimates}

Smirnov et al. $[25,26]$ point out that estimating precision and errors accumulation is necessary for large scale simulations of complex chemically reacting gas dynamics. A definite error occurs in integration at each step, which is dependent on spatial resolution and numerical solver. This error can be expressed in absolute or relative values. Accumulation of error takes place for successive time steps.

Table 1 Geometrical parameters of the reference nozzles

\begin{tabular}{llllll}
\hline Case & HCA & $\begin{array}{l}d_{t} \\
(\mathrm{~m})\end{array}$ & $\begin{array}{l}d_{\mathrm{e}} \\
(\mathrm{m})\end{array}$ & $\begin{array}{l}L \\
(\mathrm{~m})\end{array}$ & ER \\
\hline TCM2 & 10.0 & 0.006 & 0.40 & 1.13 & 4444 \\
HEG & 6.5 & 0.011 & 0.88 & 3.75 & 6400 \\
\hline
\end{tabular}


Table 2 Geometrical parameters based on the FD-21 nozzle

\begin{tabular}{llllll}
\hline Case & $\begin{array}{l}H C A \\
\left({ }^{\circ}\right.\end{array}$ & $\begin{array}{l}d_{t} \\
(\mathrm{~m})\end{array}$ & $\begin{array}{l}d_{\mathrm{e}} \\
(\mathrm{m})\end{array}$ & $\begin{array}{l}L \\
(\mathrm{~m})\end{array}$ & ER \\
\hline 1 & 9.0 & 0.020 & 2.00 & 6.52 & 10,000 \\
2 & 9.0 & 0.010 & 1.00 & 3.26 & 10,000 \\
3 & 9.0 & 0.040 & 2.00 & 6.46 & 2500 \\
4 & 9.0 & 0.060 & 2.00 & 6.32 & 1111 \\
\hline
\end{tabular}

The relative error of integration in one-dimensional case $S_{1}$ is proportional to the mean ratio of cell size $\Delta L$ to the domain size $L_{1}$ in the direction of integration in power depending on scheme accuracy [25]:

$$
S_{1} \approx\left(\frac{\Delta L}{L_{1}}\right)^{k+1}
$$

Where $k$ is the order of accuracy of numerical scheme. In the presence of several directions in integration, the errors [25] are written as

$$
S_{\text {erro }} \approx \sum_{i=1}^{2} S_{i}
$$

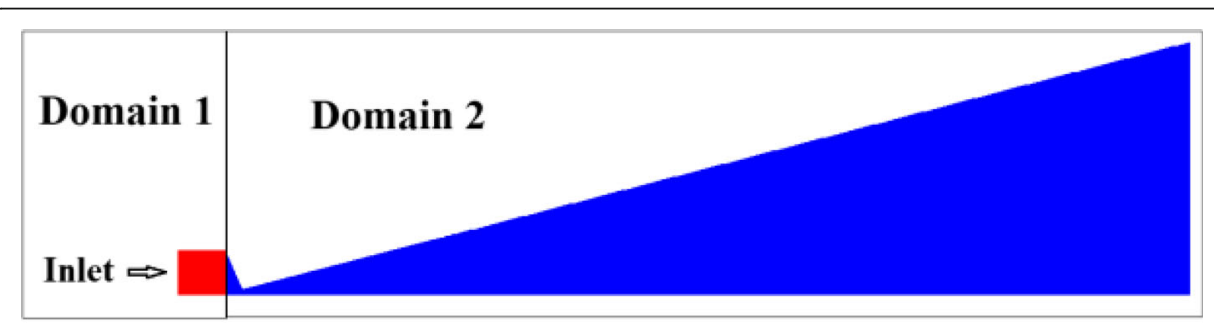

(a) The different domains

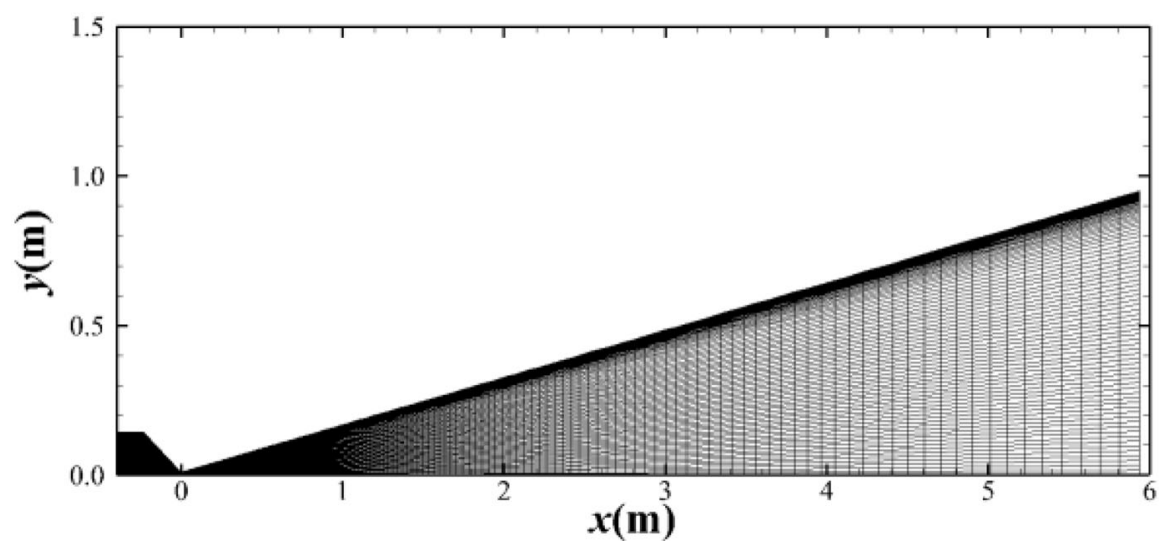

(b) Computational grid

Fig. 1 Computational domain. (a) The different domains. (b) Computational grid 
Table 3 Initial conditions

\begin{tabular}{lllllllll}
\hline Case & $P_{0}$ & $T_{0}$ & $C_{\mathrm{N} 2}$ & $C_{\mathrm{O} 2}$ & $C_{\mathrm{NO}}$ & $C_{\mathrm{N}}$ & $C_{\mathrm{O}}$ & $\begin{array}{l}C_{\mathrm{NO}+} \\
(\%)\end{array}$ \\
\hline 1 & $(\mathrm{MPa})$ & $(\mathrm{K})$ & $(\%)$ & $(\%)$ & $(\%)$ & $(\%)$ & $(\%)$ & 0.01 \\
2 & 101.3 & 6500 & 69.08 & 4.72 & 14.50 & 0.68 & 11.00 & 0.02 \\
\hline
\end{tabular}

The allowable value of total error $S_{\max }$ [25] is defined by the user of the simulator. For initial and boundary conditions are usually not known with higher accuracy, $S_{\max }$ should be between $1 \%$ and $5 \%$. Then the following inequality should be satisfied.

$$
S_{\text {erro }} \cdot \sqrt{n} \leq S_{\max }
$$

Where $n$ is the number of time steps in Navier-Stokes equations integration.

Another important characteristic is introduced for the results of supercomputer simulations. The ratio of the maximal allowable number of time steps to the actual number of time steps is defined as [25]:

$$
R_{s}=n_{\max } / n
$$

Table 4 shows the accumulation of error for the grid resolution and physical time simulations. The allowable error was assumed at 5\%. For present numerical simulations, all results demonstrate high reliability, but it is not always appropriate to simulate longer steps.

\subsection{Verification of the calculation method}

To verify the calculation method, the comparisons with the TCM2 [4] and HEG [5] results are made. For the TCM2 case, the initial condition is based on Case 1 in Table 3, and the normal scale is selected. Figure 2 shows the centerline vibrational temperature $T_{\mathrm{V}}$ and translational temperature $T$ distribution. The $T_{\mathrm{V}, \mathrm{N} 2}$ is the vibrational temperature of $\mathrm{N}_{2}$ and is about $2400 \mathrm{~K}$, and $T_{\mathrm{V}, \mathrm{O} 2}$ is the vibrational temperature of $\mathrm{O}_{2}$ and is about $1000 \mathrm{~K}$. The unified vibrational temperature $T \mathrm{v}$ is about $2290 \mathrm{~K}$ in this paper. Considering the mass ratio of $\mathrm{N}_{2}$ to $\mathrm{O}_{2}$ in the flow, this value is reasonable. The centerline evolution of vibrational temperature and translational temperature are plotted, as shown in Fig. 3. The results of the freezing position and temperature are in good agreement with the reference. Figure 4 shows the centerline Mach number distribution, and the variation of about $5 \%$ is predicted. The discrepancy can be explained by the different vibrational modeling, resulting in different translational temperature $T$ (static temperature). Table 5 shows the comparison of the Mach number and species mass

Table 4 Error estimates

\begin{tabular}{lll}
\hline Case & TCM2 & HEG \\
\hline Allowable error & $5 \%$ & $5 \%$ \\
Grid resolution & $1251 \times 201$ & $1251 \times 201$ \\
Physical time simulated (ms) & 3.5 & 5.0 \\
Number of time steps & 3500 & 5000 \\
Accumulated error & $1.23 \times 10^{-7}$ & $1.23 \times 10^{-7}$ \\
Allowable number of time steps & $1.63 \times 10^{11}$ & $1.63 \times 10^{11}$ \\
Reliability Rs & $4.67 \times 10^{7}$ & $3.27 \times 10^{7}$ \\
\hline
\end{tabular}




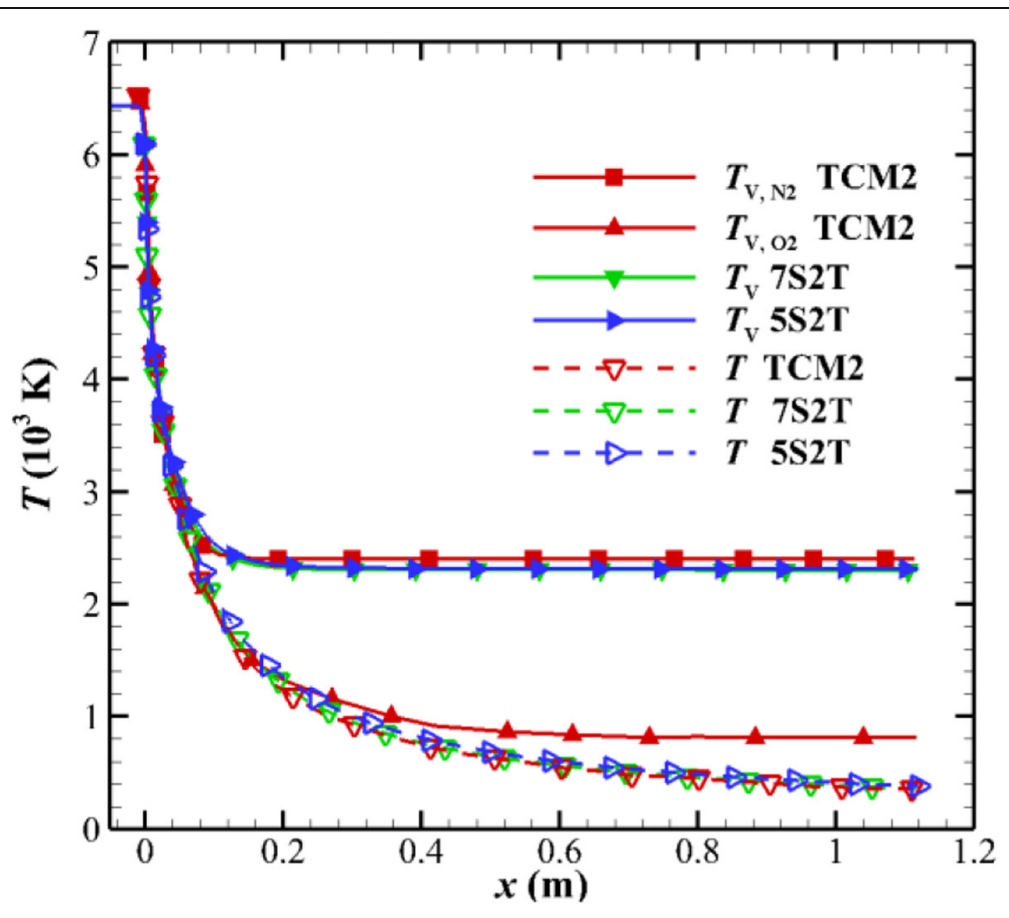

Fig. 2 Comparison of the centerline temperature distributions

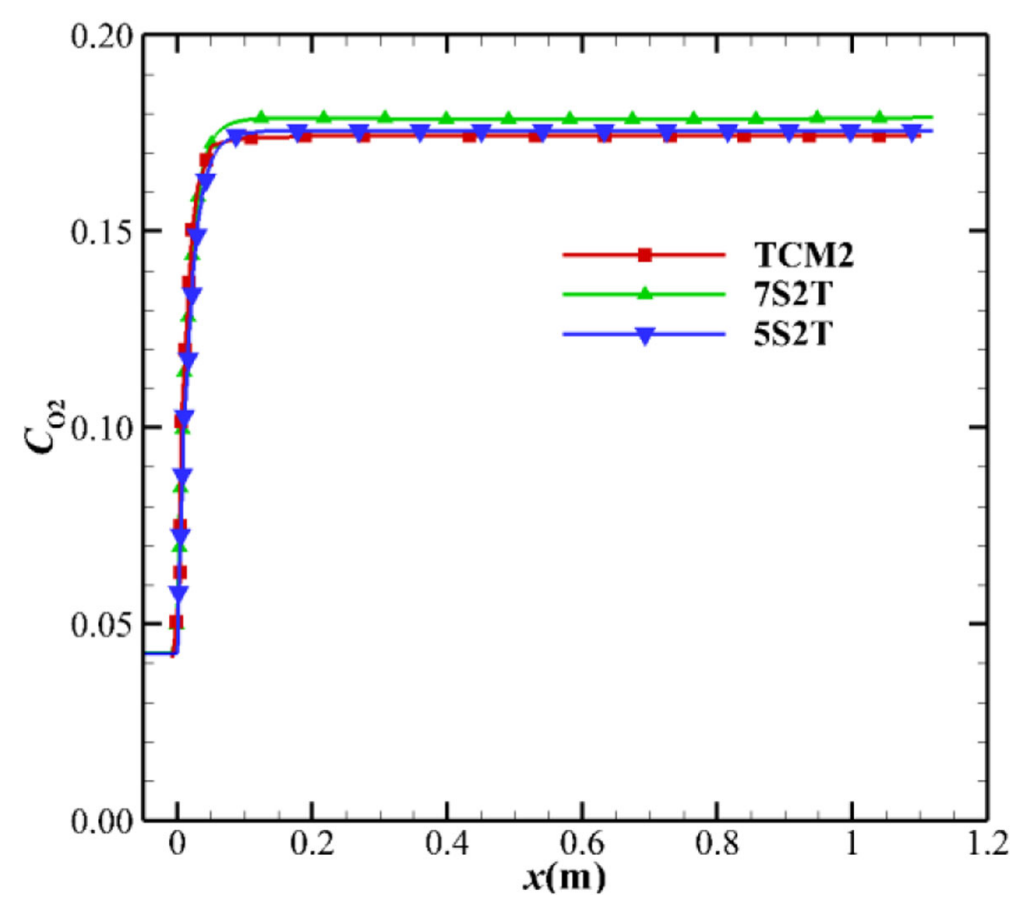

Fig. 3 Comparison of the centerline $\mathrm{O}_{2}$ mass fraction distributions 


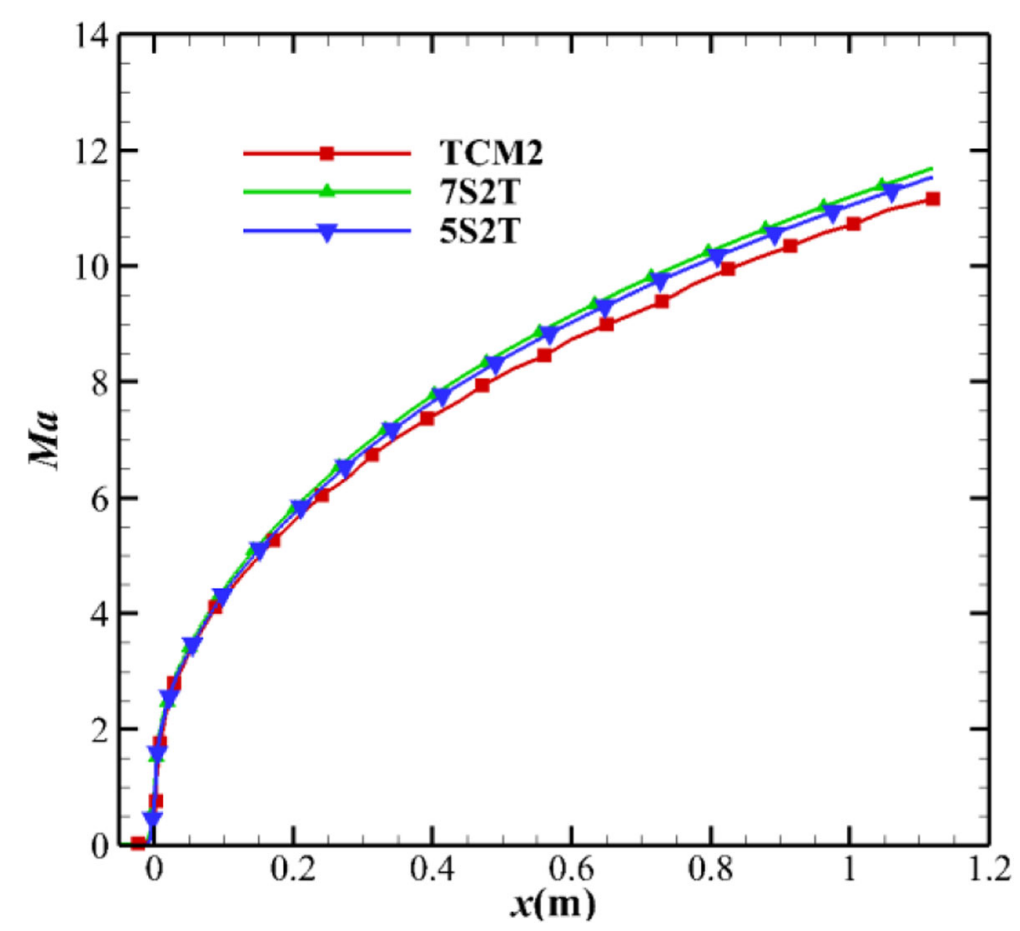

Fig. 4 Comparison of the centerline Mach number distributions

fraction in the nozzle exit. The accuracy of the static pressure $P$ and translational temperature $T$ is verified by the HEG nozzle. For the HEG case, the initial condition is based on Case 2 in Table 3. The calculation results are compared with the results for the reference [5], as shown in Table 6.

The calculation results of the nozzles of TCM2 and HEG in this paper agree well with the reference values $[4,5]$. The discrepancy calculated by comparing the main reference values is nominally $5 \%$ or less for all the cases considered. The variation can be explained. There are three main reasons for these differences. First, the vibrational modeling modifies the translational temperature, as deduced from Eq. (10). Second, there are the different expressions of the transport coefficients. The species $\mathrm{NO}^{+}$and $\mathrm{e}^{-}$belong to the micro-species. The results verify the positive determination of the relevant parameter settings and the accuracy of the procedure. Third, the turbulence energy could decrease some other energy in an isolated system. When the total temperature exceeds $6000 \mathrm{~K}$, there are trace species such as electrons, NO+. It is more appropriate to use 7 -species, so the following calculation uses 7 -species.

Table 5 Comparison of flow parameters in the TCM2 nozzle

\begin{tabular}{llllllll}
\hline Results & $\begin{array}{l}T \\
(\mathrm{~K})\end{array}$ & $\mathrm{Ma}$ & $\begin{array}{l}\mathrm{C}_{\mathrm{N2}} \\
(\%)\end{array}$ & $\begin{array}{l}\mathrm{C}_{\mathrm{O} 2} \\
(\%)\end{array}$ & $\begin{array}{l}C_{\mathrm{NO}} \\
(\%)\end{array}$ & $\begin{array}{l}C_{\mathrm{O}} \\
(\%)\end{array}$ & $\begin{array}{l}C_{\mathrm{N}} \\
(\%)\end{array}$ \\
\hline TCM2 & 356 & 11.2 & 73.23 & 17.43 & 7.44 & 2.04 & - \\
$7 \mathrm{~S} 2 \mathrm{~T}$ & 358 & 11.6 & 73.27 & 17.82 & 7.60 & 1.31 & $2.6 \mathrm{E}-7$ \\
$5 \mathrm{~S} 2 \mathrm{~T}$ & 360 & 11.5 & 73.17 & 17.57 & 7.41 & 1.93 & $1.5 \mathrm{E}-8$ \\
\hline
\end{tabular}


Table 6 Comparison of flow parameters in the HEG nozzle

\begin{tabular}{|c|c|c|c|c|c|c|c|c|}
\hline Results & $\begin{array}{l}P \\
(\mathrm{~Pa}) \\
\end{array}$ & $\begin{array}{l}T \\
(\mathrm{~K}) \\
\end{array}$ & $\begin{array}{l}u_{\infty} \\
(\mathrm{m} / \mathrm{s})\end{array}$ & $\begin{array}{l}C_{N 2} \\
(\%) \\
\end{array}$ & $\begin{array}{l}\mathrm{C}_{\mathrm{O} 2} \\
(\%) \\
\end{array}$ & $\begin{array}{l}C_{\mathrm{NO}} \\
(\%) \\
\end{array}$ & $\begin{array}{l}C_{O} \\
(\%) \\
\end{array}$ & $\begin{array}{l}C_{N} \\
(\%) \\
\end{array}$ \\
\hline HEG & 713 & 694 & 4776 & 73.56 & 13.40 & 5.09 & 7.96 & $1.0 \mathrm{E}-8$ \\
\hline $7 \mathrm{~S} 2 \mathrm{~T}$ & 701 & 723 & 4842 & 74.01 & 13.75 & 4.96 & 7.25 & 1.4E-7 \\
\hline $5 \mathrm{~S} 2 \mathrm{~T}$ & 705 & 720 & 4823 & 73.94 & 13.48 & 5.03 & 7.83 & 1.8E-8 \\
\hline
\end{tabular}

\section{Discussion of results}

\subsection{Freezing point position}

Numerical results of the different scale nozzles are now presented. The centerline evolution of the vibrational temperature $T_{\mathrm{V}}$ and translational temperature $T$ are plotted in Fig. 5. Not far downstream of the nozzle throat, the larger-scale nozzle has a slightly higher translational temperature. The vibrational temperature modifies the translational temperature, as deduced from the kinetic energy in Eq. (10). Compared with the translational temperature, the vibrational temperature is more affected by the absolute scale. The larger the scale is, the further away from the throat the freezing point is, and the lower the vibrational temperature is. The vibrational temperature of $0.5 \mathrm{NS}, \mathrm{NS}, 2 \mathrm{NS}$, $5 \mathrm{NS}$ is $2613,2298,2036,1755$, respectively. In this initial condition, the absolute scale of the nozzle is increased tenfold and the vibrational temperature is reduced by $858 \mathrm{~K}$, as shown in Fig. 5. The freezing point moves down the nozzle throat as the nozzle scale increases. At the centerline vibrational temperature in the different nozzle scales (from $0.5 \mathrm{NS}$ to $5 \mathrm{NS}$ ), the distances $x_{\mathrm{f}}$ from the freezing point to the throat are $451 \mathrm{~mm}, 1241$ $\mathrm{mm}, 3091 \mathrm{~mm}$, and $9712 \mathrm{~mm}$. The freezing point diameters $d_{\mathrm{f}}$ of their corresponding

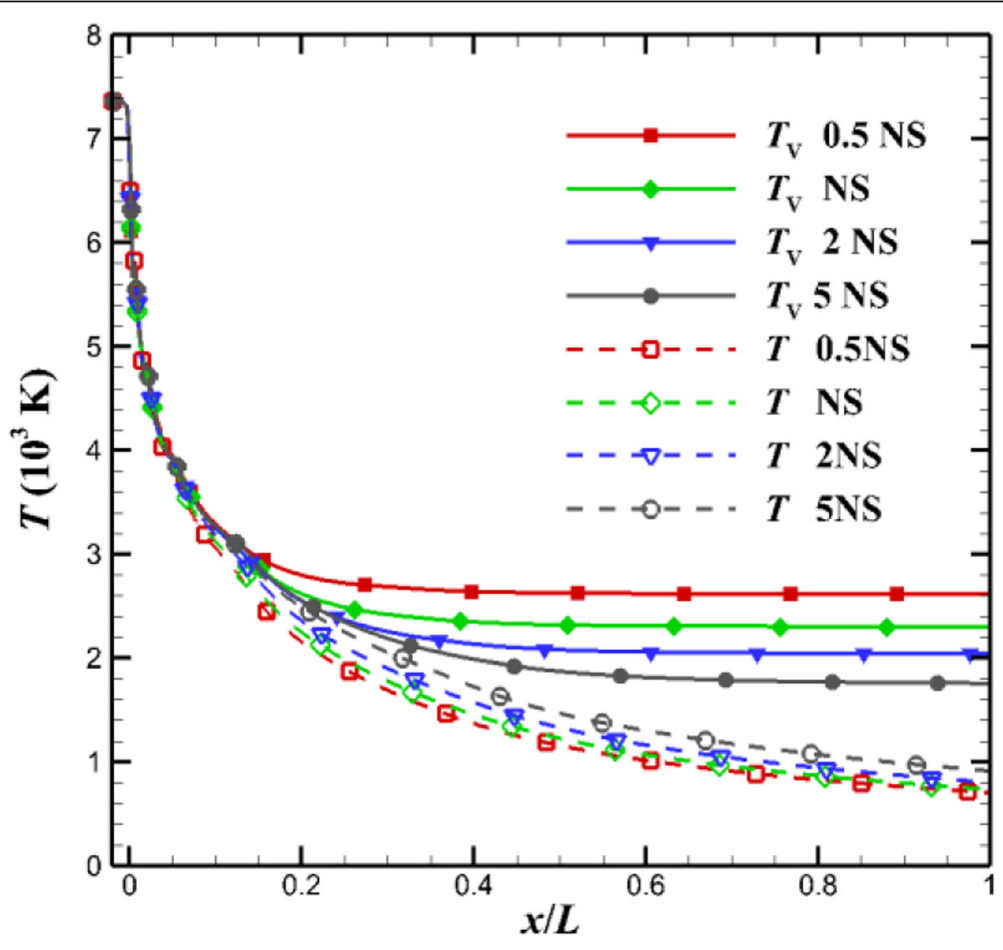

Fig. 5 Comparison of the centerline temperature distribution based on the HEG nozzle 


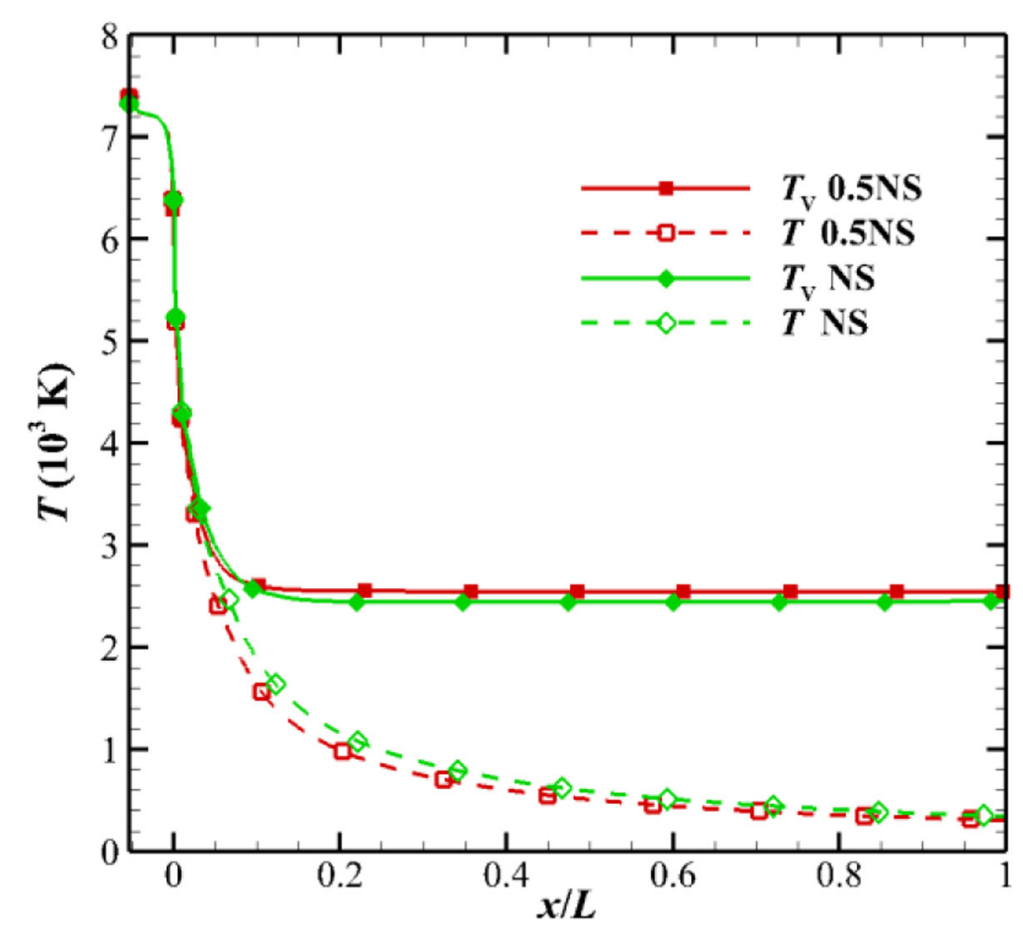

Fig. 6 Comparison of the centerline temperature distribution based on the FD-21 nozzle

nozzles are $15.7 \mathrm{~mm}, 39.3 \mathrm{~mm}, 92.2 \mathrm{~mm}$, and $276.1 \mathrm{~mm}$. The ratio $d_{\mathrm{f}} / d_{\mathrm{t}}$ of the freezing point diameter to the throat diameter is $2.86,3.57,4.19$, and 5.02 , respectively. The thermochemical non-equilibrium scale effects are also suitable for the nozzle of FD-21. Figure 6 is a comparison of 0.5NS and NS flow field temperatures. At the centerline vibrational temperature in the 0.5NS and NS nozzles, the distances $x_{\mathrm{f}}$ are $281 \mathrm{~mm}$ and $875 \mathrm{~mm}$. The freezing point diameters $d_{\mathrm{f}}$ of their corresponding nozzles are $98.1 \mathrm{~mm}$ and $254.1 \mathrm{~mm}$, and the ratios $d_{\mathrm{f}} / d_{\mathrm{t}}$ are 9.81 and 12.71 , respectively. The absolute scale not only affects the translational temperature and vibrational temperature of the nozzle flow field but also the freezing point. Those phenomena can be explained in the following aspects.

(1) As the nozzle scale increases, the pressure gradient around the throat decreases (see Fig. 7). The pressure downstream of the throat increases, which shortens TVERT, as deduced from Eq. (28). Additionally, the decrease of pressure gradient makes the flow velocity decrease and the flow time increase. Both lengthen the transition from equilibrium to freezing, and the flow is close to the equilibrium flow.

(2) Since the nozzles use the same inlet conditions, the velocity $u$ at the nozzle exit is almost identical [27], which is consistent with $h \approx u^{2} / 2$. Because of the freezing of vibrational energy, the increase of the kinetic energy of the airflow in nozzle mainly comes from the translational energy, which leads to the decrease of translational temperature $T$. 


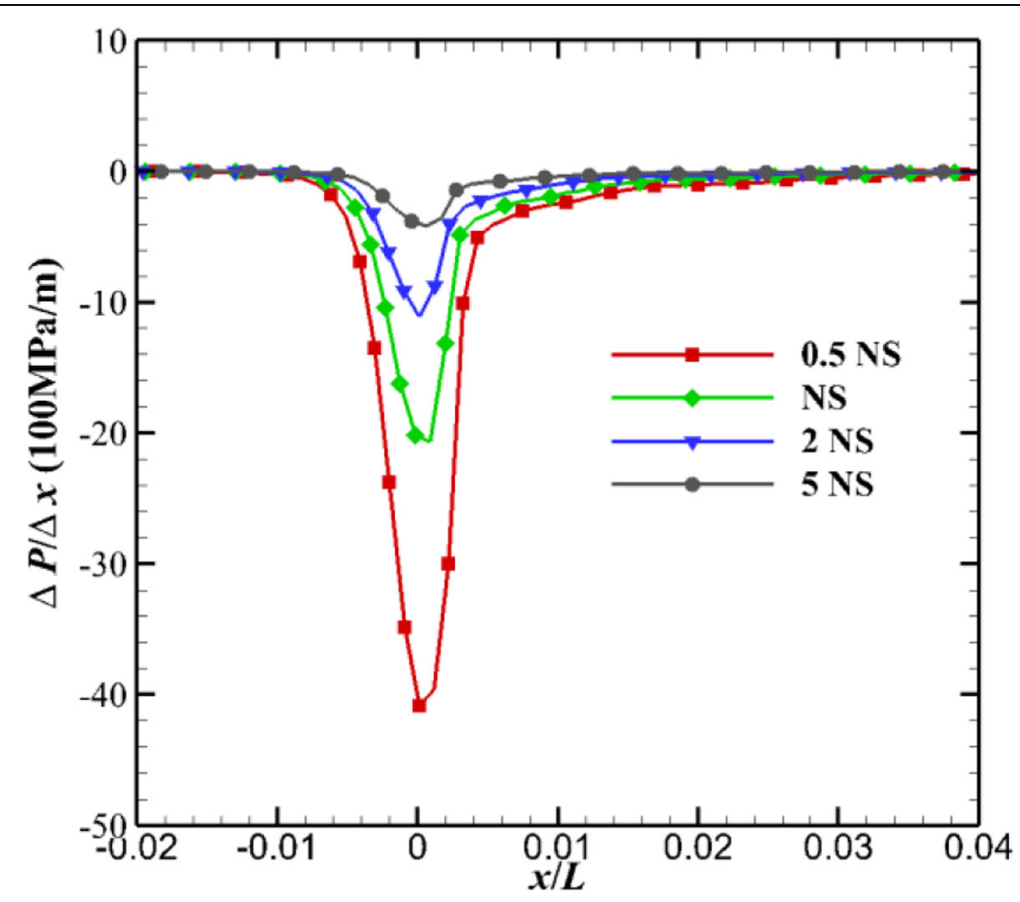

Fig. 7 Comparison of the centerline pressure gradient distribution based on the HEG nozzle

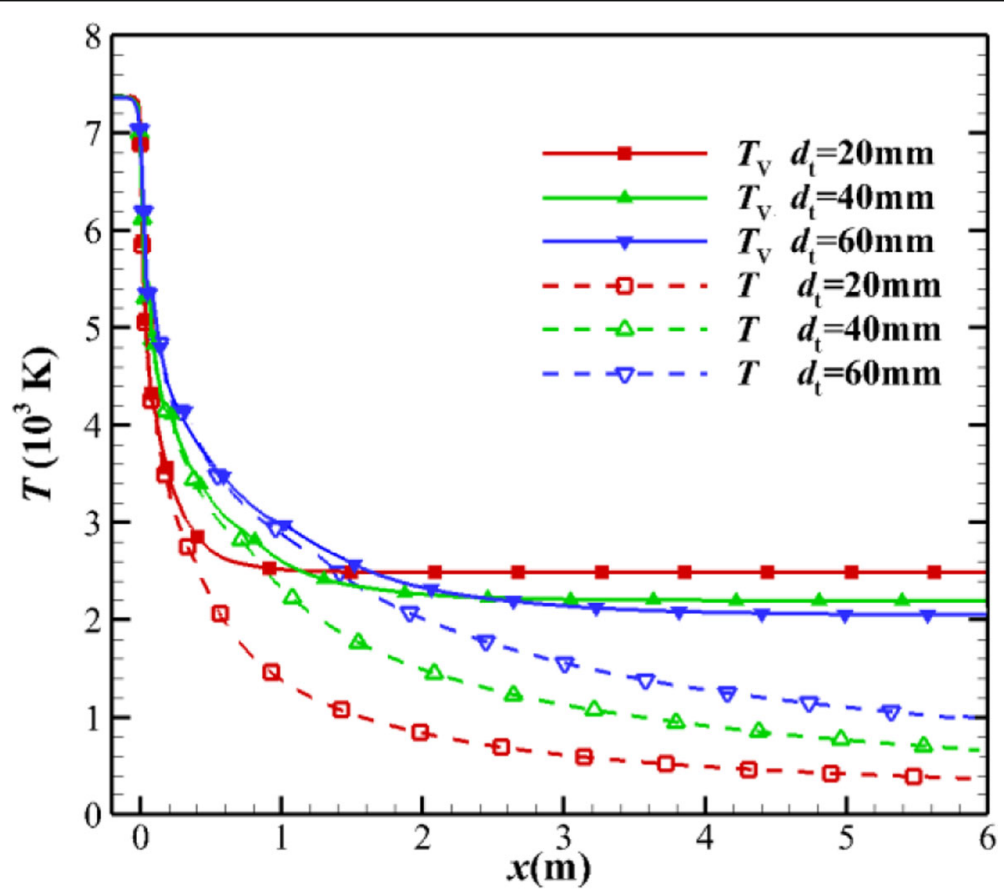

Fig. 8 Comparison of centerline temperature distributions based on the different throat diameter 
As can be seen from the above conclusion, the flow is frozen not far downstream of the high enthalpy flow throat. Cases 1,3 and 4 in Table 1 investigate the thermochemical nonequilibrium scale effects by changing the diameter of the throat alone. Figure 8 shows the distribution of vibrational temperature and translational temperature along the centerline of nozzle. For the throat radius $d_{\mathrm{t}}$ is $20 \mathrm{~mm}, 40 \mathrm{~mm}$, and $60 \mathrm{~mm}$, the freezing temperatures are $2442 \mathrm{~K}, 2207 \mathrm{~K}$, and $2140 \mathrm{~K}$, respectively. The distances $x_{\mathrm{f}}$ from the freezing point to the throat are $0.717 \mathrm{~m}, 1.568 \mathrm{~m}$, and $3.030 \mathrm{~m}$. The freezing point diameters $d_{\mathrm{f}}$ of their corresponding nozzles are $0.254 \mathrm{~m}, 0.536 \mathrm{~m}$, and $1.018 \mathrm{~m}$. The ratio $d_{\mathrm{f}} / d_{\mathrm{t}}$ of the freezing point diameter to the throat diameter is $12.7,13.4$, and 16.9 , respectively. As the throat radius increases, the freezing point moves away from the throat. They can be explained in the following aspects.

(1) The effects of the throat diameter are the same as the scale effects of the nozzle. As the nozzle diameter increases, the pressure gradient around the throat decreases (see Fig. 9), and the flow velocity around the throat decreases (See Fig. 10) and the flow time increases. Both lengthen the transition from equilibrium to freezing, and the flow is close to the equilibrium flow.

(2) In thermal equilibrium, the increase of the kinetic energy of the gas comes from both molecular translational energy and molecular vibrational energy. Therefore, thermal equilibrium causes the translational temperature and vibrational temperature to decrease. When the vibrational energy freezes, the increase in the kinetic energy of the gas comes only from the translational kinetic energy. The nozzle outlet speed is almost unchanged, which makes the reduction of translational energy deeper and the translational temperature lower.

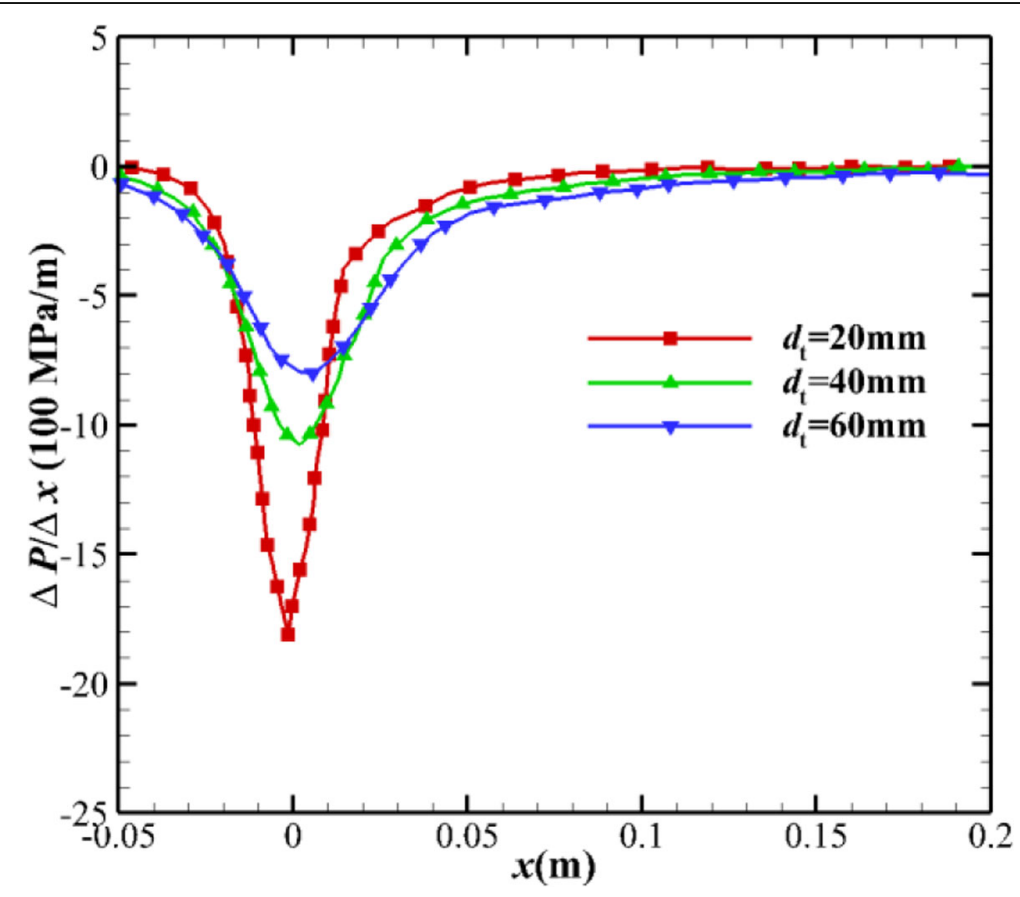

Fig. 9 Comparison of centerline pressure gradient distribution based on the different throat diameter 


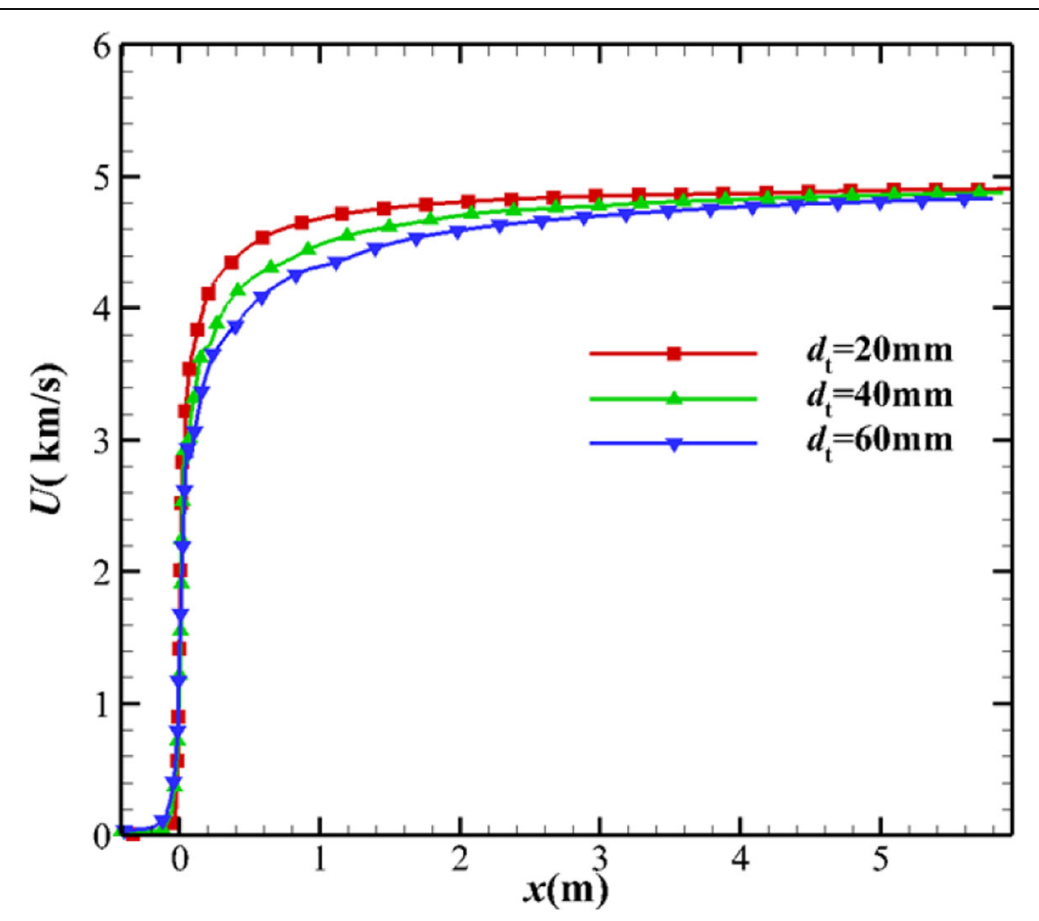

Fig. 10 Comparison of centerline velocity distributions based on the different throat diameter

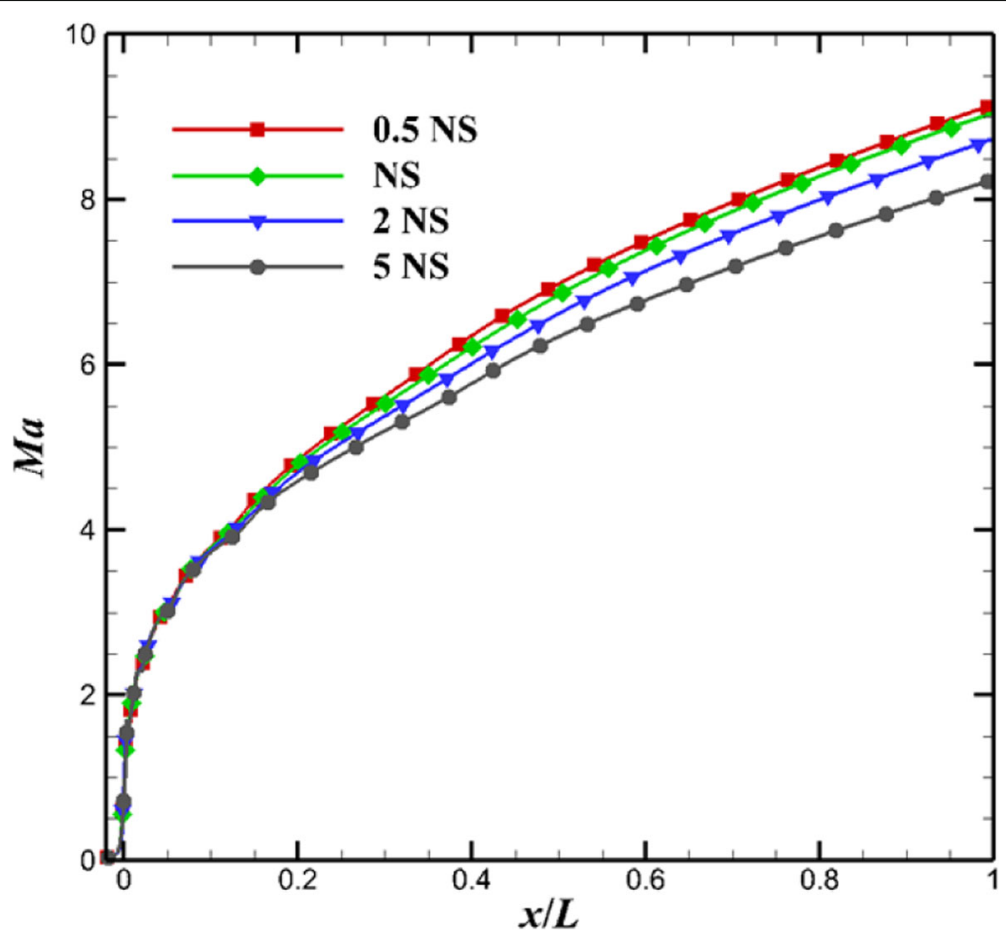

Fig. 11 Comparison of the centerline Mach number distribution based on the HEG nozzle 


\subsection{Flowfield parameters}

Figure 11 shows the Mach number distribution along the centerline. Before the freezing point, the value and evolution of the Mach number are the same. After the freezing point, this phenomenon has changed. It can be explained by the freezing of the vibrational levels. As the nozzle scale increases, the vibrational temperature decreases and the translational temperature increases. With the increase of the nozzle scale, the flow gradually approaches the thermodynamic equilibrium state. As the translational temperature increases, the local sound speed increases (see Table 5), resulting in the decrease in the Mach number. Figure 12 can also prove this. The larger the size is, the larger the ratio of the exit uniform area radius to the exit radius is, which will make the exit Mach number smaller. This is in contradiction with the assumption that the thicker the boundary wall of the nozzle wall and the smaller the Mach number under the same area ratio. It can be known by combining Figs. 11 and 12. The influence of thermochemical non-equilibrium scale effects on Mach number is more important than the viscous scale effects.

Cases 1, 3 and 4 in Table 2 are employed to study the effect of the variation throat diameter on the Mach number, as shown in Fig. 13. When the throat diameter increases, the flow is close to the equilibrium state. More vibrational energy is transmitted to the translational energy, which makes the translational temperature rise, as deduced from the kinetic energy in Eq. (10). The change in Mach number due to ER and non-equilibrium effects is much more pronounced than the change in Mach number caused by ER alone.

Figures 14 and 15 show the changes of $\mathrm{O}_{2}, \mathrm{O}$ and $\mathrm{NO}$ in the axial direction based on the HEG nozzle, respectively. The positions where these components change are the

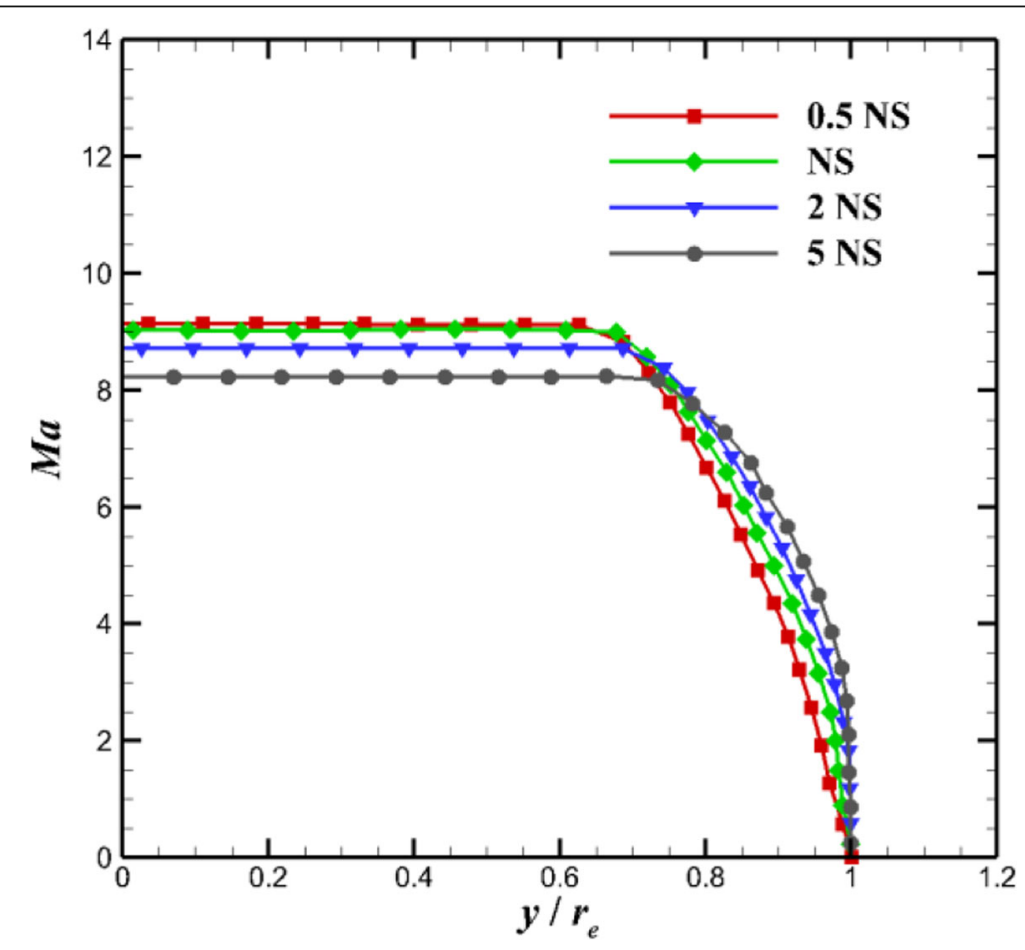

Fig. 12 Comparison of the exit Mach number distribution based on the HEG nozzle 


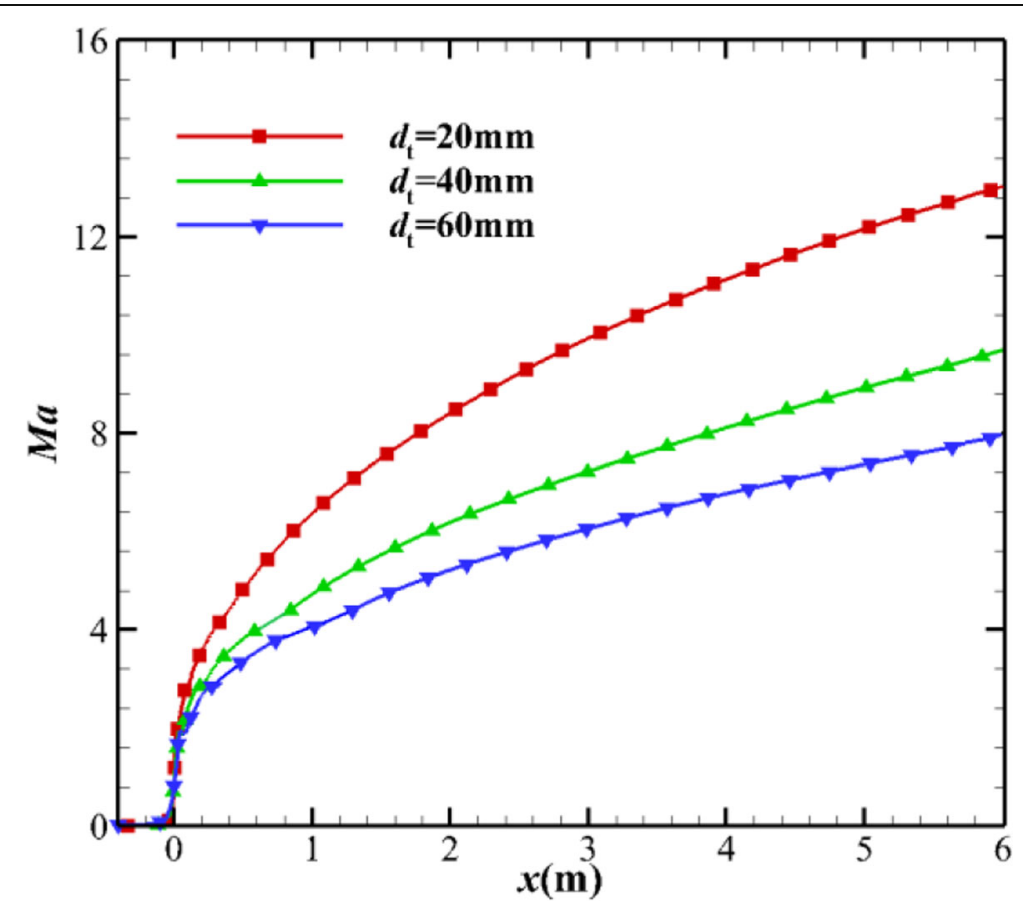

Fig. 13 Comparison of the exit Mach number distribution based on the FD-21 nozzle

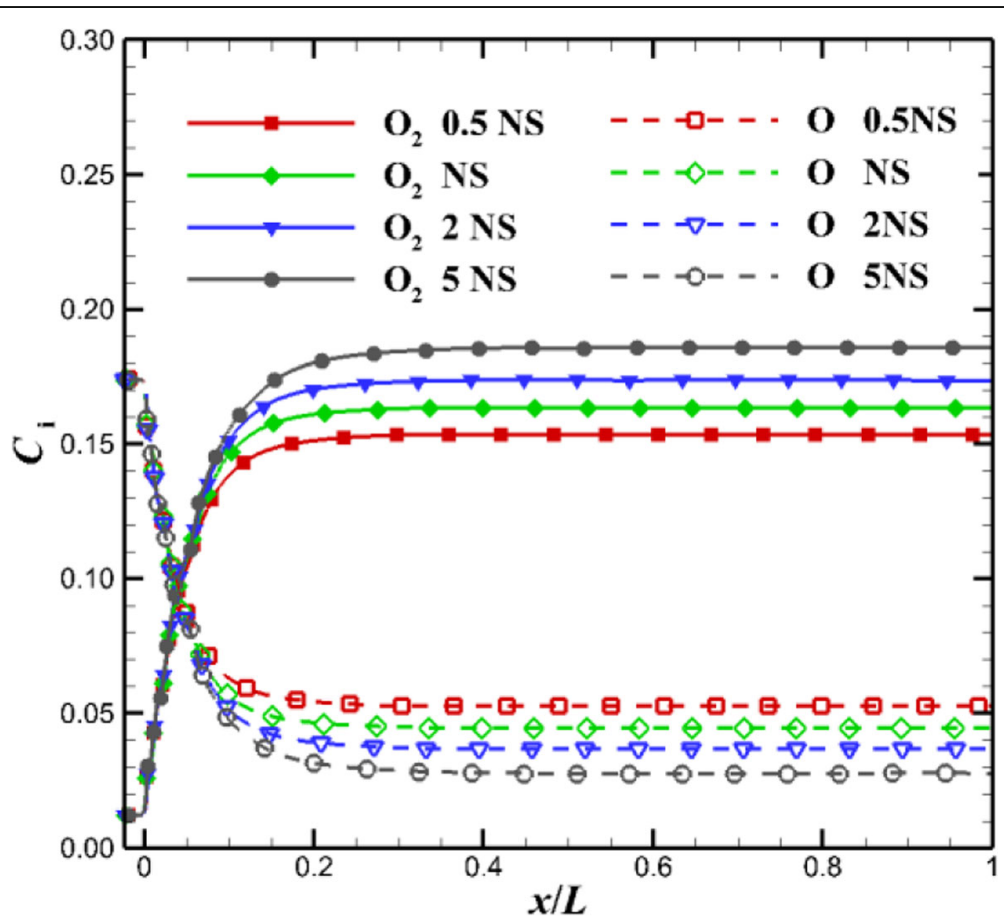

Fig. 14 Comparison of the centerline $\mathrm{O}_{2}$ and $\mathrm{O}$ mass fraction distribution based on the HEG nozzle 


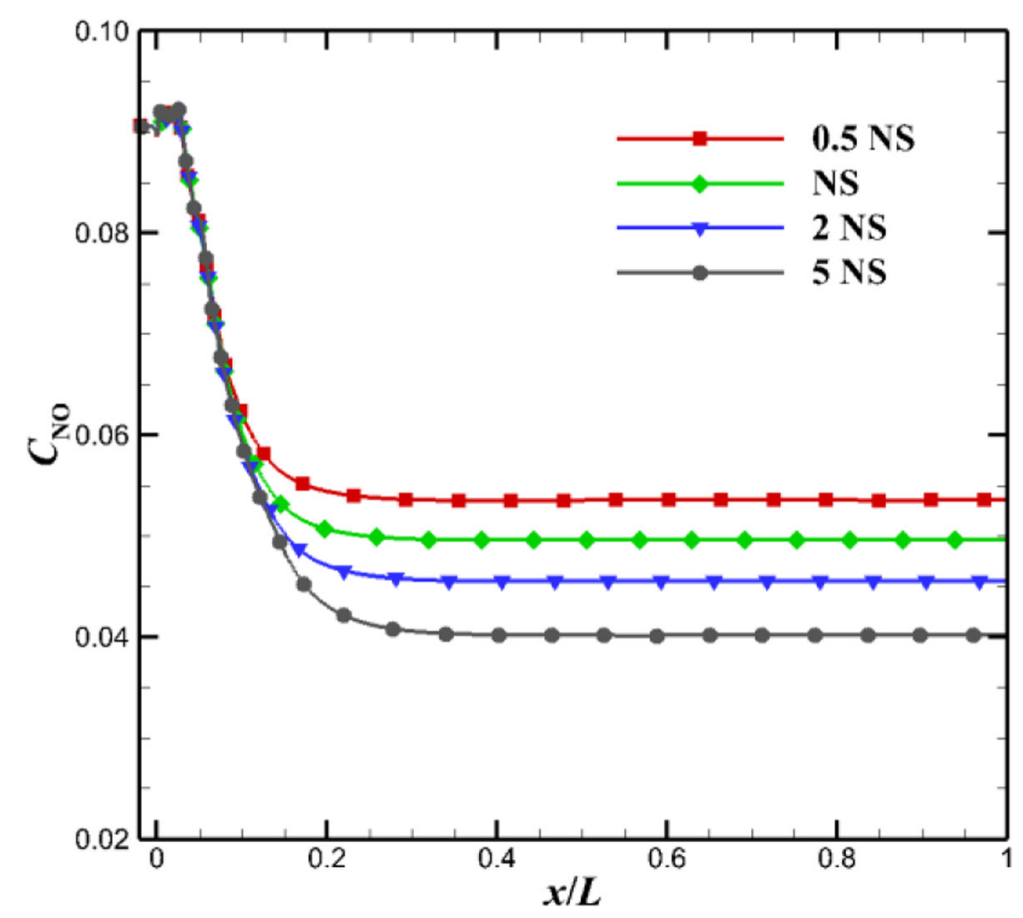

Fig. 15 Comparison of the centerline Mach number distribution based on the HEG nozzle

upstream of the freezing point, which is consistent with the changing trend of the vibrational temperature. The flow parameters depend on the dissociation of nonequilibrium before the freezing point. Tables 7 and 8 show the main flowfield parameters in the centerline of the nozzles exit, and the variation trend of the flowfield parameters can be seen. The nozzle flowfield parameters are monotonous to the absolute scale and throat diameter, such as pressure, temperature, sound velocity, Mach number, and species mass fraction. The larger the nozzle scale and throat diameter are, the larger the mass fraction of the species $\mathrm{N}_{2}$ and $\mathrm{O}_{2}$ is, but the smaller the mass fraction of the species $\mathrm{NO}, \mathrm{O}, \mathrm{N}, \mathrm{NO}^{+}$is. The species $\mathrm{N}$ and $\mathrm{NO}^{+}$are trace species, which are not listed here.

As can be seen from Tables 7 and 8 , when the nozzle scale increases, the degree of the thermal non-equilibrium decreases and the frozen vibrational energy decreases, so that the kinetic energy of the airflow, namely the speed $u_{\infty}$, increases slightly.

\section{Conclusions}

As analyzed in the paper, the high enthalpy nozzle has the thermochemical nonequilibrium scale effects, which have a certain influence on the flow field parameters of

Table 7 Comparison of flow parameters in the centerline at nozzle outlet in the HEG nozzle

\begin{tabular}{llllllllll}
\hline Results & $P$ & $T$ & $a$ & $u_{\infty}$ & $M a$ & $\begin{array}{l}C_{\mathrm{N} 2} \\
(\%)\end{array}$ & $\begin{array}{l}C_{\mathrm{O} 2} \\
(\%)\end{array}$ & $\begin{array}{l}C_{\mathrm{NO}} \\
(\%)\end{array}$ & $\begin{array}{l}C_{\mathrm{O}} \\
(\%)\end{array}$ \\
\hline 0.5NS & 652 & 706 & 527 & 4804 & 9.1 & 74.03 & 15.34 & 5.35 & 5.24 \\
NS & 701 & 723 & 536 & 4842 & 9.0 & 74.21 & 16.35 & 4.96 & 4.55 \\
2NS & 737 & 801 & 558 & 4869 & 8.7 & 74.40 & 17.36 & 4.55 & 4.46 \\
5NS & 881 & 917 & 596 & 4890 & 8.2 & 74.62 & 18.57 & 4.02 & 4.02 \\
\hline
\end{tabular}


Table 8 Comparison of flow parameters in the centerline at nozzle outlet based on the FD-21

\begin{tabular}{|c|c|c|c|c|c|c|c|c|c|}
\hline Results & $\begin{array}{l}P \\
(\mathrm{~Pa})\end{array}$ & $\begin{array}{l}T \\
(\mathrm{~K})\end{array}$ & $\begin{array}{l}a \\
(\mathrm{~m} / \mathrm{s})\end{array}$ & $\begin{array}{l}u_{\infty} \\
(\mathrm{m} / \mathrm{s})\end{array}$ & $\mathrm{Ma}$ & $\begin{array}{l}C_{\mathrm{N} 2} \\
(\%)\end{array}$ & $\begin{array}{l}\mathrm{C}_{\mathrm{O} 2} \\
(\%)\end{array}$ & $\begin{array}{l}C_{\text {NO }} \\
(\%)\end{array}$ & $\begin{array}{l}C_{O} \\
(\%)\end{array}$ \\
\hline $0.5 \mathrm{NS}$ & 63 & 301 & 342 & 4852 & 13.4 & 73.66 & 16.24 & 6.12 & 3.94 \\
\hline NS & 69 & 343 & 367 & 4903 & 13.2 & 74.12 & 16.00 & 5.05 & 4.82 \\
\hline$d t=40$ & 453 & 670 & 511 & 4875 & 9.5 & 74.31 & 16.84 & 4.73 & 4.10 \\
\hline$d t=60$ & 1489 & 984 & 619 & 4832 & 7.8 & 74.42 & 17.43 & 4.49 & 3.64 \\
\hline
\end{tabular}

the nozzle exit. For a given half cone angle and expansion ratio, the thermochemical non-equilibrium scale effects of the high enthalpy nozzle mainly have the following consequences:

(1) As the nozzle scale and expansion ratio increase, the degree of the thermal nonequilibrium decreases, and the frozen vibrational energy decreases, and translational temperature increases. The larger nozzle scale and nozzle expansion ratio can effectively suppress the thermochemical non-equilibrium flow, and is more suitable for simulating the flight environment.

(2) The absolute scale affects the freezing point of the high enthalpy nozzle. The larger absolute scale and expansion ratio cause the freezing state of the vibrational dynamics to be delayed. The freezing point moves down the nozzle throat as the nozzle scale and expansion ratio increase.

(3) As the nozzle scale increases, the static pressure, and translational temperature at the nozzle exit increase slightly, but the Mach number and vibrational temperature decrease significantly. The larger the nozzle scale and expansion ratio are, the larger the mass fraction of the species $\mathrm{N}_{2}$ and $\mathrm{O}_{2}$ is, but the smaller the mass fraction of the species $\mathrm{O}, \mathrm{N}, \mathrm{NO}$, etc is.

\section{Nomenclature}

$0.5 \mathrm{NS}$ halved normal scale

NS Normal scale

2NS doubled normal scale

$5 \mathrm{NS}$ quintupled normal scale

5S2T 5-species two-temperature model

7S2T 7-species two-temperature model

$n s$ the number of species, which is equal to 5 or 7

$n t$ the number of species that remove electrons from $n s$

\section{Acknowledgements}

The authors gratefully acknowledge the financial support of the National Key Research and Development Plan of China through the project No. 2019 YFA0405200 and 2019YFA0405300, National Natural Science Foundation of China No.11672283, and China Scholarship Council No.201704980060.

\section{Authors' contributions}

JS conceived of the study, designed the study and collected the data. All authors analysed the data and were involved in writing the manuscript. All authors read and approved the final manuscript.

\section{Funding}

The financial support of the National Key Research and Development Plan of China through the project No. 2019YFA0405200 and 2019YFA0405300, National Natural Science Foundation of China No.11672283, and China Scholarship Council No.201704980060. 
Availability of data and materials

All the data and materials are available in this paper.

\section{Competing interests}

The authors do not have any possible conflicts of interest.

Received: 1 April 2020 Accepted: 17 July 2020

Published online: 10 August 2020

\section{References}

1. Anderson JD (2006) Hypersonic and high-temperature gas dynamics, 2nd edn. AIAA, Virginia

2. Bushnell DM (2006) Scaling: wind tunnel to flight. Annu Rev Fluid Mech 38:111-128

3. Zeng M, Lin Z, Feng H, Qu Z (2005) Numerical analysis of non-equilibrium scale effects in hypersonic nozzle. J. Propulsion Technol 26(1):38-41 (Chinese)

4. Zeitoun D, Boccaccio E, Druguet MC, Imbert M (1994) Reactive and viscous flow in hypersonic nozzles. AlAA J 32(2): $333-340$

5. Hannemann K (2003) High enthalpy flows in the HEG shock tunnel: experiment and numerical rebuilding. 41st AIAA Aerospace Sciences Meeting and Exhibit, 6-9 Jan, Reno

6. Hannemann K, Itoh K, Mee DJ, Hornung HG (2016) Free piston shock tunnels HEG, HIEST, T4 and T5. Experimental Methods of Shock Wave Research. Springer, New York, pp 181-264

7. Zhao W, Jiang ZL, Saito T, Lin JM, Yu HR, Takayama K (2005) Performance of a detonation driven shock tunnel. Shock Waves 14:53-59

8. MacLean M, Candler G, Holden M (2005) Numerical evaluation of flow conditions in the LENS reflected shock-tunnel facilities. 43rd AIAA Aerospace Sciences Meeting and Exhibit, 10-13 Jan, Reno

9. Shen J, Ma H, Li C, Chen X, Bi Z (2017) Initial testing of a 2m Mach-10 free-piston shock tunnel. 31st International Symposium on Shock Waves, 9-14 July, Nagoya

10. Deutsches Zentrum für Luft - und Raumfahrt (DLR) (2018) The high enthalpy shock tunnel Göttingen of the German Aerospace Center (DLR). J Large-Scale Res Facilities 4:A133

11. Miró FM, Beyak ES, Pinna F, Reed HL (2019) High-enthalpy models for boundary-layer stability and transition. Phys Fluids 31:044101

12. Marineau EC, Hornung HG (2009) High-enthalpy nonequilibrium nozzle flow of air: experiments and computations. 39th AIAA Fluid Dynamics Conference. 22-25 June, San Antonio

13. Wang Y, Hu Z, Liu Y, Jiang Z (2016) Starting process in a large-scale shock tunnel. AIAA J 54(4):1240-1249

14. Chen X, Shen J, Bi Z, Ma H (2019) Review on the development of the free-piston enthalpy impulse wind tunnel and its testing capacities. J Exp Fluid Mech 33(4):65-80 (Chinese)

15. Shen J, Chen X, Bi Z, Ma H (2018) Review on experimental technology of high enthalpy shock tunnel. Acta Aerodynamica Sinica 36(4):543-554 (Chinese)

16. Park C (1989) Assessment of two-temperature kinetic model for ionizing air. J.Thermophysics 3(3):233-244

17. Gnoffo PA, Gupta RN, Shinn JL (1989) Conservation equations and physical models for hypersonic air flows in thermal and chemical nonequilibrium. NASA-TP-2867

18. Gupta RN, Yos JM, Thompson RA Lee KP (1990) A review of reaction rates and thermodynamic and transport properties for an 11-species air model for chemical and thermal nonequilibrium calculations to 30000K. NASA RP-1232

19. Palmer G, Wright MJ (2003) A comparison of methods to compute high temperature gas thermal conductivity. 36th AIAA Thermophyscics Conference, 23-26 June, Orlando

20. Park C (1985). Problems of rate chemistry in the flight regimes of aeroassisted orbital transfer vehicles. Thermal Design of Aeroassisted Orbital transfer Vehicles 96:511-537

21. Jameson A, Baker TJ (1983) Solution of the Euler equations for complex configurations. 6th Computational Fluid Dynamics Conference Danvers, 13-15 July, Danvers

22. Shima E, Kitamura K (2009) On new simple low-dissipation scheme of AUSM-family for all speeds. 47th AIAA Aerospace Sciences Meeting including The New Horizons Forum and Aerospace Exposition, 5-8 Jan, Orlando

23. Spalart PR, Allmaras SR (1994) A one-equation turbulence model for aerodynamic flow. La Recherche Aérospatiale 1:521

24. Li H (2007) Numerical simulation of hypersonic and high temperature gas flow fields. Dissertation, China Aerodynamics Research and Development Center (Chinese)

25. Smirnov NN, Betelin VB, Shagaliev RM et al (2014) Hydrogen fuel rocket engines simulation using LOGOS code. Int J Hydrog Energy 39(20):10748-10756

26. Smirnov NN, Betelin VB, Nikitin VF et al (2015) Accumulation of errors in numerical simulations of chemically reacting gas dynamics. Acta Astronautica 117:338-355

27. Lu FK and Marren DE (eds) (2002) Advanced hypersonic test facilities. AIAA, Virginia

\section{Publisher's Note}

Springer Nature remains neutral with regard to jurisdictional claims in published maps and institutional affiliations. 